\title{
How Today's Libraries Can Help to Address Information Gaps for Small- and Medium-sized Enterprises: Li Ka Shing Library as an Example
}

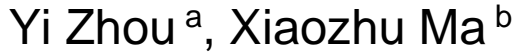 \\ Nanyang Technological University, Singapore \\ aw170016@e.ntu.edu.sg, b maxi0007@e.ntu.edu.sg
}

\begin{abstract}
Small and medium-sized enterprises (SMEs) can be considered as the backbone of a country's economy in general, which have been connected with the development of economy in both developing and developed countries directly. Meanwhile, libraries have been an important source of information in modern society. They nowadays emphasized the extended task in offering information services accustomed to the business's community in local area. They are considered as the primary information resource focuses for business community. In this article, we acknowledge the information gap of SMEs. Putting the Li Ka Shing library in the supply-side of information source and service for SMEs, its role is to bridge the information gap so that parties can reach each other. It is essentially a "broker" bringing SMEs and various information creators of a product or service. Li KA Shing library as a comprehensive business library which equipped with advanced facilities and professional service and management teams, has great potential to bridge the business information gap of SMEs. On top of that, we propose some solution for Li Ka Shing library to better plug the business information gap of SMEs and increase visitorship.
\end{abstract}

Keywords: Library, small and medium-sized enterprises, information gap, business.

\section{Introduction}

\subsection{Role of Libraries}

Public libraries are considered to be traditional avenues which support to provide the community with information. From the traditional point of view, they perform four primary functions: educational, informative, cultural and recreational. They make great contributions to national literacy development, socio-economic development, lifelong learning, democracy and citizenship [7]. With technology in play, digital library has become an important area of the information infrastructure. It serves similar goals, objectives and purposes as traditional library. It is a systematically organized collection of information in electronic format that may or may not be part of a traditional collection. It can also be acknowledged as the system which offers coherent access to a large, organized repository of knowledge and information to community users [8].

\subsection{Role of SMEs}

Small and medium-sized enterprises (SMEs) are identified as the backbone of a nation's economy in general, which have been connected with the development of economy in both developing and developed countries directly. They create lots of job opportunities, lesson poverty, contribute to the GDP, generate wealth, drive innovations and enhance the economy value chain to higher 'valueadded' activities, and help to balance the economic power distribution among high income and lowincome classes. SMEs fundamentally affect the economical contribution all over the world [6]. In Singapore, SMEs are essential in shaping the nation's economy as they account for about $90 \%$ of all establishments in Singapore.

Libraries have been an important source of information in modern society. Public libraries nowadays emphasized the extended task in offering information services accustomed to the business's community in local area. They are considered as the primary information resource focuses for business community. The origin that public libraries offer business people information services is on the basis of the Community Information Service (CIS) with examples from both the United States and Great Britain during the nineteenth century. The information dissemination towards the business 
community is a general mission of public libraries all over the world now. In spite of the varying roles of the public libraries demonstrated above, according to a number of surveys, libraries are not considered source of business information that much by the business community [4]. On the following parts, we will introduce a university library in Singapore to illustrate how it serves the business information needs of SMEs, the advantages and challenges as well as our proposed solution.

\section{About SMU Li Ka Shing Library}

\subsection{The Library Profiles}

In 24 February 2006, Li Ka Shing Library was formally opened in Singapore. The Library is named after Chairman of Cheung Kong (Holdings) Limited and Hutchison Whampoa Limited, Hong Kong businessman Dr. Li Ka-shing. The Li Ka Shing Foundation endowed to the University for scholarship and to the library for collections. This library located in 70 Stamford Road, where is the center of downtown. It is the business centre with lots of business offices and shopping malls. Its location provides convenience to SMEs whenever they need to visit to the library for information or attending events.

\subsection{Facilities and Services}

Li Ka Shing library provides a variety of learning spaces, which include 38 project rooms equipped with LCD panels, Learning Commons (open 24/7), open areas for individual and collaborative use, study booths, postgraduate lounges, learning labs, quiet zones and an Investment Studio. The library space is equipped with state-of-the-art facilities such as digital signages, express workstations, wireless network and dedicated computers with specific financial software. In the lounge on Level 2, videos, collections of lifestyles reading materials, recent issues of newspapers, magazines, games and a display of latest arrivals are all available [5].

\subsubsection{Books and Videos}

There are various publications which are related to business in the library including books, e-books, journals and videos. When you search for the key word "business", you can be accessed to $28777 \mathrm{e}-$ books. 8425 books and 5750 journals. Audio visual system is also complete and advanced, users can watch 832 videos in business area.

\subsubsection{Facilities}

Li Ka Shing Library is well equipped with advanced hardware devices. For example, there is an investment studio on the third floor, where users can access high-end finance databases under one roof. The library subscribes numerous large databases to serve the information needs of faculties and students. Furthermore, alumni in SMU can access to the Business Source Alumni Edition Database even they are not on the campus. This off-campus database service is applied by the business community to catch up with the latest trends in areas related to management and relevant fields. It offers access to over 1,360 full text business magazines and journals, of which 590 are peer-reviewed, and the publications involve almost every aspect of business including management, marketing, economics, accounting, finance and so on [9].

SMU students, faculty and staff who need assistance with database searching or customized help with their research projects may make an appointment with a librarian who specializes in related subjects, such as accounting, business and economics.

The research librarians can also collaborate with students and faculty to integrate subject-specific workshops and seminars that cover resources relevant to their courses, as well as involvement in various classroom project.

\subsubsection{Membership Scheme}

Students, faculty and staff are all entitled to free library membership. Similarly, every SMU Alumni Association member has walk-in access towards Li Ka Shing Library. On the other hand, external users may apply for membership. There are three types of external membership: access-only 
membership, corporate membership, and personal membership. In Singapore, all government departments and industrial/commercial firms are eligible to apply for a library corporate membership, although it does have strict rules like "On each visit, each card is able to admit at most three employees from the organization" [10].

\subsubsection{Workshop, Seminars, Talks, Conferences \& Symposiums}

There are many conferences and symposiums held in the library, for example, "Asian Luxury Branding Research Conference". Its purpose is to produce and deliver high quality and independent academic research on the luxury brand industry in the market of Asia. This kind of conference can offer a site to discuss, cogitate and expound on extensive issues about luxury branding — from different views of diverse stakeholders [11].

The library also organizes professional talks and seminars on various topics for students, faculty, staff and external guests.

\subsubsection{Entrepreneurs' Corner @ SMU}

It is just like a watering hole for innovators, entrepreneurs, investors, industry partners and business mentors. People can recognize and engage investors, technology providers and business mentors via this network. Meanwhile, investors and mentors can catch sight of the next big company and cooperate with talented entrepreneurs. Everyone will be encouraged to present their innovative business and be allowed to seek new opportunities for the development of entrepreneur in the scale of industry partnerships, mentorship and fund-raising, looking for possible partnerships and collaborations [14].

\section{Business Information Needs of SMEs}

In today's global economy, it is the business information that shows potential for making contributions to the wealth and success of the economy and, therefore, regarded as the access to gain sustainable competitive superiority for modern business enterprises. Singapore enterprises operating in the global marketplace ought to bear the competitive pressures from new alternative products and technologies and from other producers. Business managers thus are in desperate need of an input of competitive business information and should manage and take advantage of this information. However, being small and medium sized, SMEs have limited resource to access business information as compared with MNCs. As a result, they might face problems if they do not keep up with the rapid changes taking place in the business environment especially in view of information exploration now taking place. Due to SMEs are less structured, cannot afford hiring information specialists and have limited fiscal resources as compared with their counterparts, they require more established flows of information instead of large enterprises. So how to obtain and leverage useful business information is vital for SMEs to gain sustainable competitive advantage and to facilitate decision-making [13].

The scope of business information ought to cut through every facet of business development activity like operations, start-up, growth, financing, insurance, international business, production and marketing among others.

Business information needed by SMEs are varied and different depending on the type of business activities engaged in and their phase of development. In different development stage, SMEs need different business information to facilitate their development strategies. The appropriate information - information has to be concentrated and accurate and it has to be demands based [14]. Here we adopt a three-stage business growth model to define the SME business development stage. And we also assume the main information user group for different stage.

Star-up stage (planning and preparation stage): companies have recently registered and the services/products of them are being developed and original potential customers are being validated. Operational tasks involve the most fundamental tasks such as sales and production.

Main user group: decision or police maker such as entrepreneurs, managers, directors, etc.

Business information needs focuses on: advancing information about the external circumstance, i.e., the geographic, political, technological, judicial, demographic, social, ecological, economic and 
financial environments as well as management and technological information for decision purposes, business opportunities, trends and markets, competitors, supplies of raw materials, source of funds, technology, foreign trade practices, planning cash flow, profit planning, new product development, process of setting up business/ company, preparing business plan etc. [15].

Early stage (operation and control stage): companies are producing services and products in support of early customers but would generally be of no profits. It also contains early stage companies which are profitable (e.g. the owner establishes a good relationship with the customers before building up their business and have low front-end costs for development). Control tasks guarantees resources are efficiently used in the achievement of the enterprise targets [15].

Main user group: while the company is developing, besides the management group, more information needs will be arisen from division-level personnel and task-oriented groups.

Business information needs focuses on: lots of instant information demands. This kind of information is demanded to respond to an immediate concern, which is possible to tackle ongoing tasks or projects, or daily management affairs. Such as information on changes in commodity markets, marketing strategy, supply chain management, human resource management, customer relation management, procedure improvement, product inventory control, cross-functional team management etc.

Later stage (development and expansion stage): generally, have conspicuous growth in revenue and have

generated profits for some years. Nevertheless, for some later stage firms, it is likely to temporarily dip into unpredictability in terms of profitability and sales (e.g. a firm may be demanded to invest a good deal of capital in either fixed asset acquisition or R\&D simply to sustain the business). Strategic goals focus on long-term development and expansion [2].

Main user group: with the increasing complexity and challenges, information becomes essential for senior management, specialist such as R\&D developer, investment specialist, marketing professional etc.

Business information needs focuses on: potential information requirements- this kind of information is treated as a long-run strategic resource basically. Such as creativeness and innovativeness in business, economic announcements and statistics, financial market data and detailed analysis, stock price movements, facilitation of business partnerships and referrals, business environment, market trend, latest technology, how to minimize/mitigate risks, strategy plan, investment opportunities, sustainable development, etc.

\section{Information Gap and Proposed Solution}

\subsection{Information Gap}

Business enterprises' demand for information will ineluctably go up in the future. Small business managers seem to have no possibility to state their information demands. Several reasons could be explained for this, they are unconscious of what information is available, and also do not know how such information could be utilized. They also lack an awareness of important business information provision agencies or institutions. Even if entrepreneurs identify their demands they rarely understand where to go for information. The findings of a survey by COMPAS Inc. suggested that in the light of information sources, business managers usually depended on "informal" sources from their suppliers, colleagues and clients. Information and learning from suppliers, colleagues and clients were usually from personal contact by phone, email, or in person. Empirical research indicates plenty of entrepreneurs depend on their personal networks in venture development and retention. Besides the personal contacts mentioned above, the Internet and social media ways like WhatsApp, Instagram, Facebook are become important informal sources [3]. There are some key formal information sources including: 


\begin{tabular}{|c|c|}
\hline 1). Courses & 6). Technical training \\
\hline 2). Business exhibitions & 7). Practical training \\
\hline 3). Internet/e-mail & 8). Banks \\
\hline 4). Business premises & 9). Associations/clubs \\
\hline 5). Government agencies & 10). Libraries \\
\hline
\end{tabular}

From the information consumer perspective, the low degree of consciousness of the public library as a venue for business information now restricts the library's effectiveness as a resource of such information [4]. There is always a perception that libraries especially university libraries are serving educational system. Another reason that libraries being the less popular source of business information to SMEs is mainly because looking for information from libraries is usually too timewasting as compared to other sources such as Internet [3].

From the library perspective, even though many university libraries have a business category that caters to the information needs of the business community, there are many restrictions. For SMU, the library resources are mainly serving students and staff. Some external memberships such as corporate membership, personal membership is offered on annual subscription basis with limited access. The nature of materials in the university library found to be mainly general or academic at the national level. At the industrial level, there is very broad range of subjects that could be useful to the SMEs. According to Mostert (1999), the significant disadvantage of the public library is that it is not addressing the pratical demands of the communities it is serving - neither through active participation in proactive programmes, nor in the kinds of services it offers to the public. Access to information is inadequate, which is at variance with the demand for effective competition in the global marketplace. The SMEs need tailor-made information approachs - i.e., business information services that assess, verify and apply information to a specialized business issue [16].

\subsection{Proposed Solution}

We acknowledge the information gap of SMEs as we analyzed in the previous session. Putting the Li Ka Shing library in the supply-side of information source and service for SMEs, its role is to bridge the information gap so that parties can reach each other. It is essentially a "broker" bringing SMEs and various information creators of a product or service. Li KA Shing library as a comprehensive business library which equipped with advanced facilities and professional service and management teams, has great potential to bridge the business information gap of SMEs. In the following session, we propose some solution for Li Ka Shing library to better plug the business information gap of SMEs and increase visitorship.

\subsubsection{Plug the Business Information Gap of SMEs}

\section{Profiling SMEs}

In the information industry, it is essential to understand the demand and supply side of information. Knowing who your customers are is crucial. Knowing who they are, what and when they do and where they do it enables the library to better define its audience and more effectively engage with them. Many survey and practice linked high small business failure to the lack of relevant and credible business information at each stage of business development. Libraries should be better placed to configure objective business information solutions for supporting specific SMEs sector throughout all the stages of business growth. Profiling SMEs allows the library to define a clear set of messages and imagery for specific information consumers to improve their experience.

By understanding specific business information needs of SMEs in different stages, the library can be repositioned as business community development resource centers by providing business information solutions that are not only value-based but also sector-specific, easy to retrieve, use and understand.

Establishment of a separate business resource centre and including the industry element in the management board 
While the objective of the university library is mainly to support the education, it is inevitable for the library to implement some restrictions for external users to make sure student and faculty's information need is served in priority. In view of the current restriction of information access by corporate users, the library can set up a separate business sector to facilitate the information need of the business community while not disturbing its service to the university. This separate business sector handles various information needs from physical collections to digital resources for SMEs as well as events organized for the business community. In implementation of the business sector, we would propose the following solutions:

(a)To have library staff knowledgeable in business matter or have business experience to responsible for the business sector. The staff should be able to build collection in business information, to develop the training and advisory role of the library, information packaging for corporate users, creating more awareness, organizing events and forums for capacity building. They should be able to identify specific information needs of SMEs in different stage so as to tailor-made business information provision sector in an effective and attractive way.

(b)To add on industry element in the management board. The SMU library set up a new Library Advisory Committee (LIBRAC) in 2012. The LIBRAC is to advise the Library on its support of the teaching, learning, research and community-building needs of the University. LIBRAC will also serve as a forum for discussing SMU community's library and information needs and expectations. We can see the LIBRAC is set up for serving the SMU internal community thus its membership consists of faculty members from various schools, two student representatives as well as the University Librarian. Since SMU is a university specialized in business and management, it would be beneficial if a sub-committee on business sector can be developed, for example, Library Business Advisory Committee. A chairman from the business community can be appointed by the senior management in SMU or recommended by the business community or even by the Singapore Chamber of Commerce. Representatives from star-ups and well-developed SMEs can be invited to be the members in the committee. Faculty member from the business school should be the official member in the committee. The membership can be on annual basis so as to maintain its vitality and engage the business community to obtain broad contribution. The University Librarian and responsible staff in the business sector overseas the committee. Committee meetings could be held on regular base, agenda should be focus on the support to the business information needs for the business community.

(c)Building a network of borderless library. The library should be fully aware of the impact of globalization and technology. So as to respond to the particular demands of the SMEs, business information services should create value via bringing together information from different sources both international and local. This enables the integration of the SMEs into national and global value chains. There is a need for collaboration between various trade and industrial organizations, private enterprises, professional bodies and government departments to offer SMEs with a comprehensive range of business information, advice and facilities. The library should also try to link local and overseas library and information providers so as to allow users and librarians access a wide range of information databases from their homes, offices and libraries. Figure 1 indicates the business information support connections of the business community and other partners. It suggests Donor, Society/public, Agencies and Government are indispensable stakeholders in business information generation and/or provision. It is also now of almost no possility to isolate the business community from Information and Communication Technologies (ICTs) when we talk about information provision as a result of the roles ICTs, particularly the telephone and Internet services, play in information provision. The requirement of the market would exert pressure on the need for quality business information all the time [17]. The Internet is a more economical framework that a Digital Library can be more effective to provide networked access to information sources located throughout the world. It is observed that the electronic journals available in the Digital Library provide a rather substantial volume of information that is needed by the SMEs. Thus, it may be suggested that SMEs may browse through these journals in their search for information. Mobile phones have been regarded as the most universal ICT all over the world. Mobile technologies have made information and 
communication access very convenient and timely to users from the comfort of their own homes and offices and from wherever they are while on the move with their cellular phone's units or PDAs (personal digital assistants). The library should continue to develop its digital library to serve the business community and explore the mobile technology application in information provision and interaction with SMEs. The library should also utilize the social media technologies in serving SMEs, such as information publication \& collection, social interaction etc. [18].

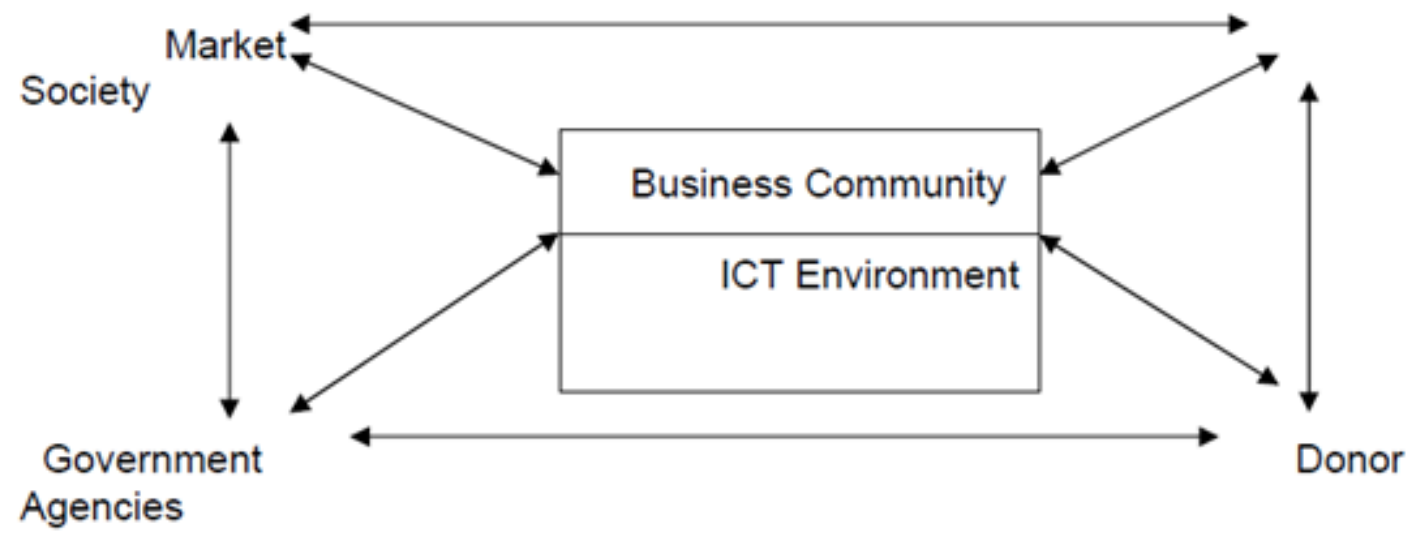

Fig 1. Business information support relationships

Source: Lavrin and Zelko (2003), ICT-based business information support services for MSME development

\subsubsection{Increase Visitorship}

While the solution to plug the information, gap proposed in the above session have positive effect on increasing the visitorship to the library, here we also propose some more concrete solution to help the library increase the visitorship both physically and digitally.

(d)To help SMEs overcome the constraints of awareness and skill shortages. As we analyzed in the information gap session, a major reason for the information gap might, simply, be short of awareness on the SMEs of the potential advantages from the information in library. Skills weaknesses are also a primary limit - the smallest firms usually offer their workforce no training about where and how to get useful business information. The library can organize training and other human resource development activities to improve skills in the use, management and promotion of business information access. This would reinforce the capacity of information supply and enhance the users' participation. It is recommended that the tailor-made training programmes ought to be conducted in an interactive way. A sharing of experiences on business information search and use by successful entrepreneurs is needed

(e)Be proactive in services delivery. For instance, the library ought to be encouraged to produce talking books that satisfy information demands of the SMEs. The talking books in the pattern of CDROMs, digital versatile disks and radio cassettes could be borrowed by the SMEs to access helpful business information [19].

(f)Invite SMEs for business seminars and workshops. With the establishment of the business sector and the business advisory committee, the library can better utilize the networking in the industry to organize events which tailored to their unique needs. For example, entrepreneurs and prominent representatives from SMEs can be invited by the advisory committee to be the guest speakers for specific business topics. Promotion of the events will be more extensive and active with the engagement of industrial representatives. Partnerships and collaborations can be enhanced which will help the library to develop its important role in business provision in the business community.

(g)From the university prospective, it will be also a win-win situation for SMU. By engaging the industry community, SMU can build a strong commercial network which is beneficial for students. For example, the library can set up an Enterprise-Student corner which mingle professionals and 
student and even faculties to collaborative projects including internships, competitions, research projects etc.

\section{References}

[1]. Shokane, J. s. (2003). The use of business information by small and medium-sized enterprises in Acornhoek. South African Journal of Libraries \& Information Science, 69(1), 55-61.

[2]. Xiao, L. (2011). Financing high-tech SMEs in China: a three-stage model of business development. Entrepreneurship \& Regional Development, 23(3-4), 217-234. doi: 10.1080/ 08985620903233937.

[3]. Kassim, N. A., \& Buyong, S. Z. (2010, December). Business-related information needs: A study of potential Bumiputera entrepreneurs in Malaysia. In Science and Social Research (CSSR), 2010 International Conference on (pp. 944-949). IEEE.

[4]. Gichohi, P. M., Onyancha, O. B., \& Dulle, F. W. (2017). How public libraries in Meru County, Kenya, address the business information needs of small-scale enterprises. Information Development, 33(4), 418-435.

[5]. https://library.smu.edu.sg/about-us/overview/about-us-li-ka-shing-library.

[6]. Hobohm, S. (2001). Small and medium-sized enterprises in economic development: The UNIDO experience. Journal of Economic Cooperation, 22(1), 1-42.

[7]. Chisita, C. T. (2011, August). Role of public libraries in promoting literacy in Zimbabwe: Challenges of sustaining a reading culture. In 77th IFLA World Library and Information Conference. Pueto Rico (pp. 13-18).

[8]. Li, X., \& Furht, B. (1999). Design and Implementation of Digital Libraries. In IMSA (pp. 213217).

[9]. https://library.smu.edu.sg/services/alumni.

[10]. https://library.smu.edu.sg/library-membership-overview.

[11]. https://www.smu.edu.sg/sites/default/files/business/pdf/Call-for-Papers_Final.pdf.

[12]. https://iie.smu.edu.sg/entrepreneurs-corner_1mar2017.

[13]. Mehralizadeh, Y., \& Sajady, S. H. (2006). A study of factors related to successful and failure of entrepreneurs of small industrial business with emphasis on their level of education and training.

[14]. Observer, O. E. C. D. (2000). Small and medium-sized enterprises: local strength, global reach. Policy Brief.

[15]. https://labs.openviewpartners.com/customer-segmentation/\#.W5drSvZuLIU.

[16]. Organisation for Economic Co-operation and Development. (2004). ICT, E-Business and Small and Medium Enterprises. OECD Publishing.

[17]. OECD., Dembinski, P. H., Farinelli, F., \& Lunati, M. T. (2007). Enhancing the Role of SMEs in Global Value Chains. Organisation for Economic Co-operation and Development.

[18]. Saxena, A., \& Yadav, R. D. (2013). Impact of mobile technology on libraries: a descriptive study. International Journal of Digital Library Services, 3(4), 1-13.

[19]. Okello-Obura, C., Minishi-Majanja, M. K., Cloete, L., \& Ikoja-Odongo, J. R. (2007). Assessment of business information access problems in Uganda. Partnership: The Canadian journal of library and information practice and research, 2(2). 